\title{
Design of Experiment (DoE): Implementation in Determining Optimum Design Parameters of Portable Workstation
}

\author{
Nafisa Ali Anika, Nadia Tanzeem, Himadri Sen Gupta \\ Department of Industrial and Production Engineering, Military Institute of Science of Technology (MIST), Dhaka, Bangladesh \\ Email: hgupta@ipe.mist.ac.bd
}

How to cite this paper: Anika, N.A., Tanzeem, N. and Gupta, H.S. (2020) Design of Experiment (DoE): Implementation in Determining Optimum Design Parameters of Portable Workstation. Engineering, 12, 25-32. https://doi.org/10.4236/eng.2020.121002

Received: September 11, 2019

Accepted: January 13, 2020

Published: January 16, 2020

Copyright (๑) 2020 by author(s) and Scientific Research Publishing Inc. This work is licensed under the Creative Commons Attribution International License (CC BY 4.0).

http://creativecommons.org/licenses/by/4.0/

\section{(c) (i) Open Access}

\begin{abstract}
In the modern era of manufacturing, it is important to optimize every design parameter in product development stage to reduce cost, material usage and to achieve the desired efficacy level. There are various models which serve those purposes, for instance, Design of Experiment (DoE) is used to check the parameters after adopting optimization tactics which results in reduced cost or saving operating time. In this regard, this research aims to construct a DoE model on a portable workstation to optimize its design parameters. The methodology of DOE would be a 2 level 3 factors full factorial DOE which is conducted to determine the optimal value for three design parameters (factors) which are material density, the length of the table and the length of the table stand in terms of the response which is the required time of fold ability function of the portable workstation. Based upon the evaluated interactions between the parameters, the optimized parameters are chosen for responses. Here, the resultant design parameters are at their lowest level, so the goal of time efficiency in fold ability function is achieved. This similar sort of DoE can be implemented in the furniture and other manufacturing industries who wish to optimize their material usage as well as increase efficiency and reduce cycle time.
\end{abstract}

\section{Keywords}

Design of Experiment (DoE), Portable Workstation, Design Parameters, Response Time, Efficiency Improvement

\section{Introduction}

In the design and development phase of a new product, selection of less time-consuming functionality is essential along with serving the intended pur- 
pose of that product. To select less time-consuming functionality, the design parameters must be optimized in such a way that it can function properly within least time. This optimization of design parameters should be implemented in the design stage of the product development. The purpose of the design phase is to implement all items that have been discussed in the define, measure, and analyze phases into a detailed product design [1]. Product development is an iterative process in order to cope up with the fast-changing market situations, immense price pressure and shortening of product life cycles [2]. As a result, during the design phase of the product development, the designs must be evaluated and revised extensively to bring out more coherence from that product.

This research article considers a portable workstation which has a fold ability function. The workstation consists of a desk and a chair which are joined by a hinge and can be folded. The table is supported by square stainless-steel pipe, an outer box and plywood. The table and the outer box can be folded over the chair. There are two wheels and a handle in the back of the chair which helps the workstation to move after folding. To make the product time effective, the time requirement to fold the workstation will be needed to be reduced. To solve this issue, Design of Experiments (DoE) is conducted at the design stage of product development to optimize the design parameters which affect the required folding time. DoE is a systematized approach of performing the experimentation by utilizing the principles of science and statistics, which helps in establishing relationships between the input factors and output responses [3]. It is a very useful as well as the most crucial tool for the identification to optimize the respective process conditions [4]. DoE can be applied to any system in which output information and its quality depend on many input parameters. It is an iterative procedure based on previous measurements and is able to predict better settings resulting in an improvement in the quality of the output information [5]. Among different types of design of experiments, in a full factorial design (FFD), the effect of all the factors and their interactions on the outcome(s) is investigated [6]. As this research intends to evaluate the effects and interactions of all factors, full factorial design of experiment is conducted here to obtain the optimum process parameters. Using this method, this paper gathers statistical data, analyze and evaluate them with full factorial design of experiments in order to determine the optimal design parameters.

This paper is organized as follows. Section 2 describes the research methodology and process factors. Section 3 presents the DOE model analysis and Section 4 interprets the results. Conclusions are presented in Section 5.

\section{Methodology}

Any input to the process is a factor which can be set to a desired value on the machine controller or can be selected from the available options. On the other hand, any output from a process is a response [7]. A response is the result obtained at the various level settings to which the factors are set to during an expe- 
riment. The value or attribute of a response depends on the setting of a factor. In this research paper, the response or output information is the folding time of the workstation. In this article, the response is the time required to fold the workstation. The response depends on the density of material used to make the workstation, the length of the table and the length of the table stand. So, these are the factors that are evaluated in this design of experiments to observe the changes in the output or response. The process of the foldability of the workstation is illustrated in Figure 1.

Full factorial designed experiment consists of all possible combinations of levels for all factors. The total number of experiments for studying $\mathrm{k}$ factors at 2-levels is $2^{\wedge} \mathrm{k}$ [8]. In this research, 2-level and 3 factors which means 8 full factorial design is conducted on the workstation. The list of the process factors along with their levels are represented in Table 1.

All two factor interactions are evaluated in these experiments that might affect the average process. The full factorial design is conducted to determine optimal level of factors.

\section{Design Analysis}

\subsection{Experimental Layout}

The time is measured at different levels of factors and timings are recorded three times. The experimental layout is illustrated by Table 2 .

\subsection{Pareto and Interaction Plots}

A main effects plot or Pareto plot is a plot of the mean response values at each level of a design parameter or process variable. One can use this plot to compare the relative strength of the effects of various factors [9]. In this research article, Pareto plot is used in order to determine which factors or design parameters have significant effects on the response. The Pareto plot of effects of all responses indicates the same interpretation in terms of the effects of factor on the response, Pareto plot for response 1 is shown in Figure 2.

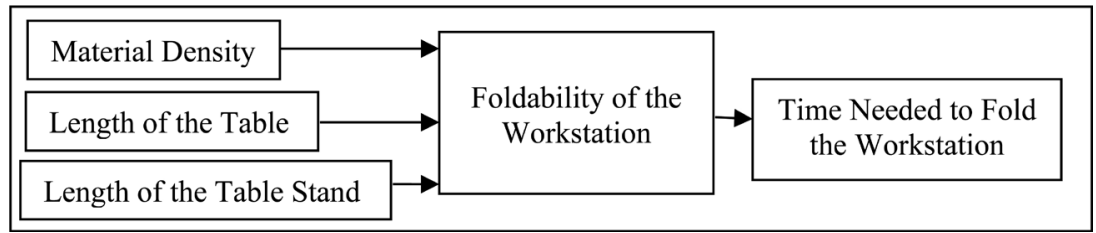

Figure 1. Schematic diagram for the folding ability of the workstation.

Table 1. Process factors with their levels and labels.

\begin{tabular}{cccc}
\hline Factors & Labels & High Level & Low Level \\
\hline Material Density & D & $680 \mathrm{~kg} / \mathrm{m}^{3}$ & $2000 \mathrm{~kg} / \mathrm{m}^{3}$ \\
Length of the Table & L & $30 \mathrm{~cm}$ & $33 \mathrm{~cm}$ \\
Length of the Table Stand & $\mathrm{S}$ & $60 \mathrm{~cm}$ & $64 \mathrm{~cm}$ \\
\hline
\end{tabular}


Table 2. Experimental layout.

\begin{tabular}{ccccccc}
\hline $\begin{array}{c}\text { No. of } \\
\text { Trials }\end{array}$ & $\begin{array}{c}\mathrm{D} \\
\left(\mathrm{kg} / \mathrm{m}^{3}\right)\end{array}$ & $\begin{array}{c}\mathrm{L} \\
(\mathrm{cm})\end{array}$ & $\begin{array}{c}\mathrm{S} \\
(\mathrm{cm})\end{array}$ & $\begin{array}{c}\text { Response 1 } \\
\text { (Time in Seconds) }\end{array}$ & $\begin{array}{c}\text { Response 2 } \\
\text { (Time in Seconds) }\end{array}$ & $\begin{array}{c}\text { Response 3 } \\
\text { (Time in Seconds) }\end{array}$ \\
\hline 1 & 680 & 30 & 60 & 30.66 & 31.20 & 30.23 \\
2 & 2000 & 30 & 60 & 26.79 & 26.57 & 26.69 \\
3 & 680 & 33 & 60 & 29.71 & 29.82 & 30.33 \\
4 & 2000 & 33 & 60 & 25.58 & 25.21 & 25.81 \\
5 & 680 & 30 & 64 & 37.75 & 37.01 & 37.32 \\
6 & 2000 & 30 & 64 & 33.24 & 32.30 & 34.01 \\
7 & 680 & 33 & 64 & 37.11 & 36.30 & 37.23 \\
8 & 2000 & 33 & 64 & 32.56 & 32.84 & 33.90 \\
\hline
\end{tabular}

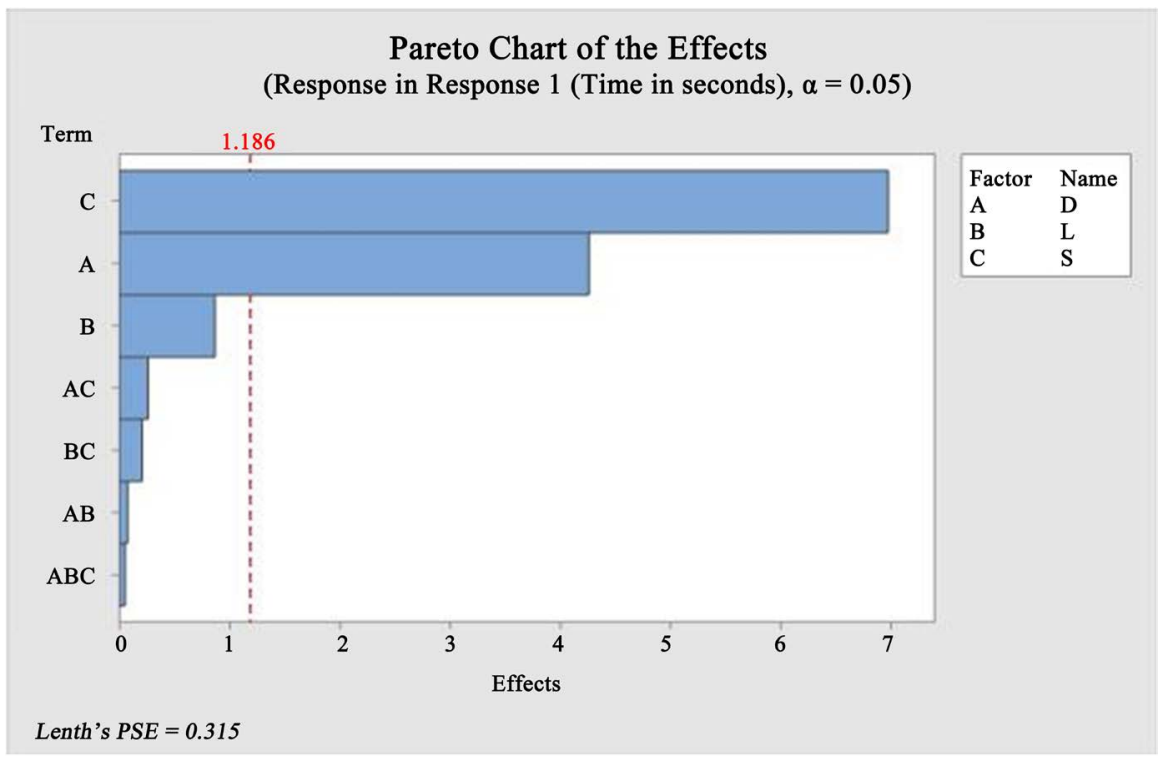

Figure 2. Pareto plot for Response 1.

An interactions plot is a powerful graphical tool which plots the mean response of two factors at all possible combinations of their settings. If the lines are parallel, this indicates that there is an interaction between the factors. Non-parallel lines are an indication of the presence of interaction between the factors [9]. Among three responses, significant interaction is seen only on response 3. Interaction plot for response 3 is illustrated Figure 3.

\section{Interpretation of Pareto and interaction plot}

From Pareto plots, it can be interpreted that material density(D) and the length of the table stand(S) has a significant effect on the foldability of the workstation. Other factors including the interactions of the factors do not show noticeable impact on the response. On the other hand, interaction plot illustrates that there is little interaction between the material density and the length of the table. But this interaction might not have much influence on the folding time of workstation which can be concluded from the Pareto chart. 


\subsection{Main and Interaction Effects Affecting the Variability in Response Time}

Screening designs provide an effective way to consider many process or design parameters (or factors) in a minimum number of experimental runs or trials (i.e. with minimum sources and budget) [10]. In our research article, a coded design matrix is established for screening and determining the notable main and interaction effects that affect process variability where standard deviation (SD) is the response. The coded design matrix is presented in Table 3. The Pareto effect in terms of SD is illustrated in Figure 4 and interaction plot is illustrated in Figure 5.

\section{Results and Discussion}

From the Pareto plot of standard deviation (Figure 4) shows none of the factors has a significant effect on variability. On the other hand, the interaction plot represents that the interaction between material density $(\mathrm{L})$ and the length of the table (L) affects the variability. From this analysis, the optimal design parameter

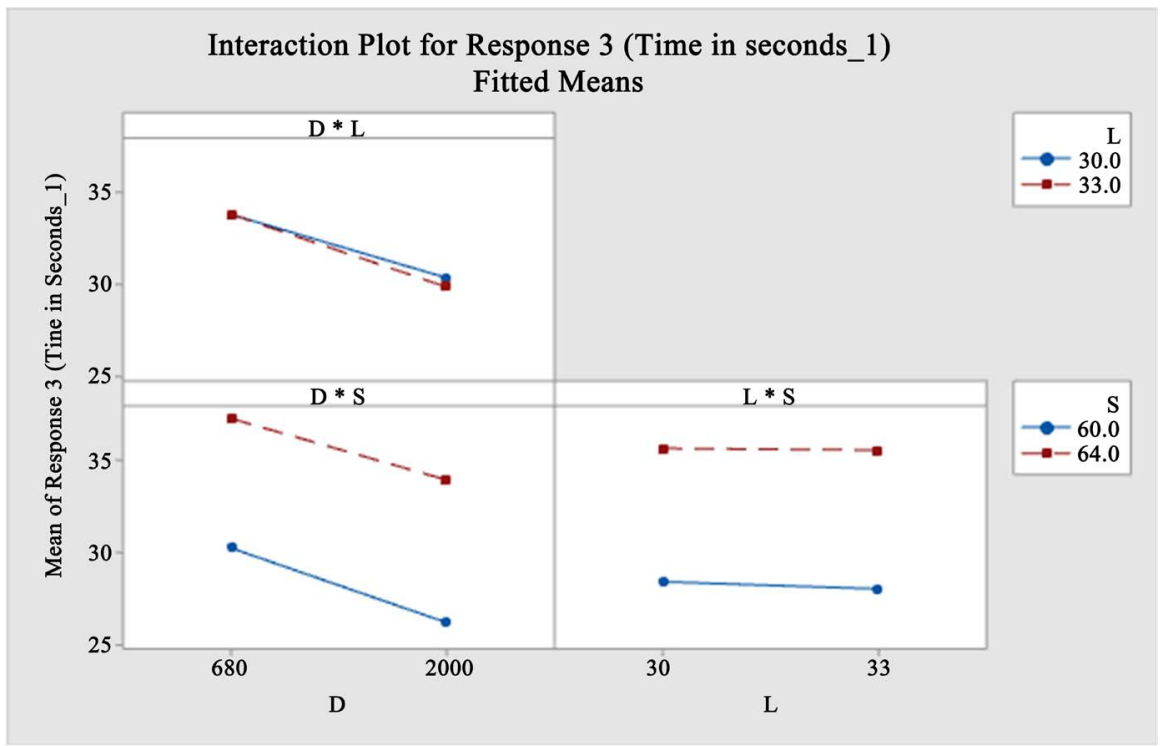

Figure 3. Interaction plot for Response 3.

Table 3. Coded design matrix.

\begin{tabular}{ccccccc}
\hline No. of Trials & $\mathrm{D}\left(\mathrm{kg} / \mathrm{m}^{3}\right)$ & $\mathrm{L}(\mathrm{cm})$ & $\mathrm{S}(\mathrm{cm})$ & $\mathrm{SD}$ & $\mathrm{NR}$ & Mean \\
\hline 1 & -1 & 1 & 1 & 30.66 & 31.20 & 30.23 \\
2 & 1 & 1 & 1 & 26.79 & 26.57 & 26.69 \\
3 & -1 & 1 & 1 & 29.71 & 29.82 & 30.33 \\
4 & 1 & 1 & 1 & 25.58 & 25.21 & 25.81 \\
5 & -1 & 1 & 1 & 37.75 & 37.01 & 37.32 \\
6 & 1 & 1 & 1 & 33.24 & 32.30 & 34.01 \\
7 & -1 & 1 & 1 & 37.11 & 36.30 & 37.23 \\
8 & 1 & 1 & 1 & 32.56 & 32.84 & 33.90 \\
\hline
\end{tabular}




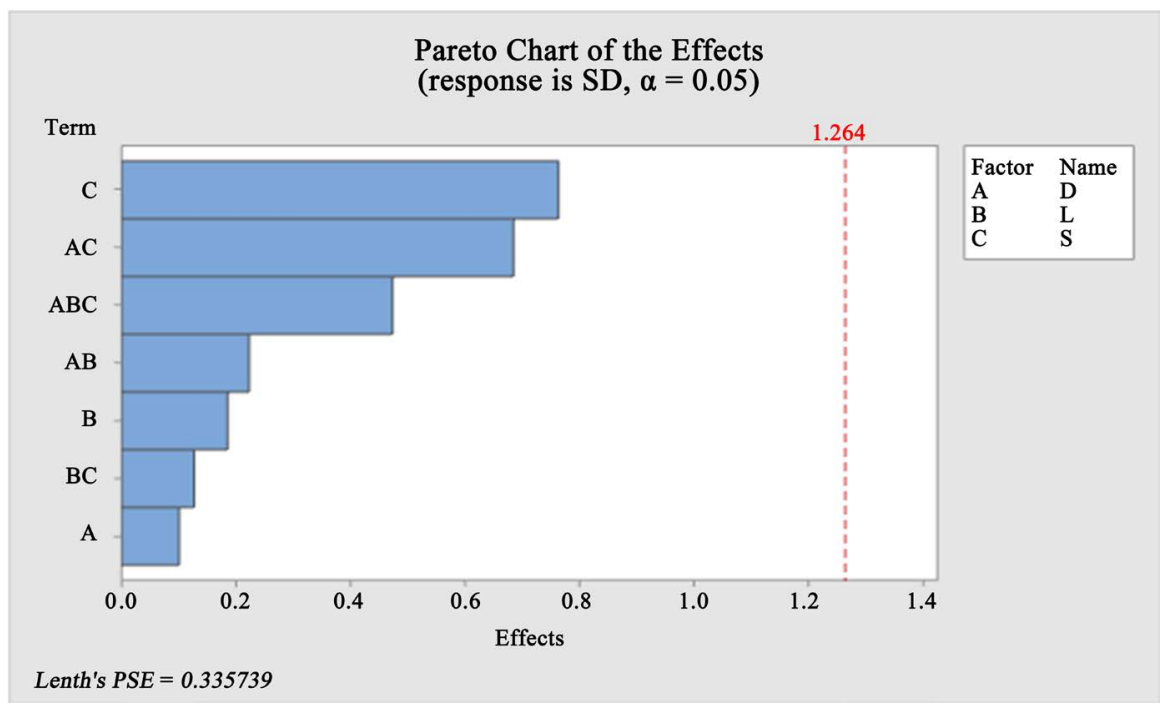

Figure 4. Pareto plot of the effects.

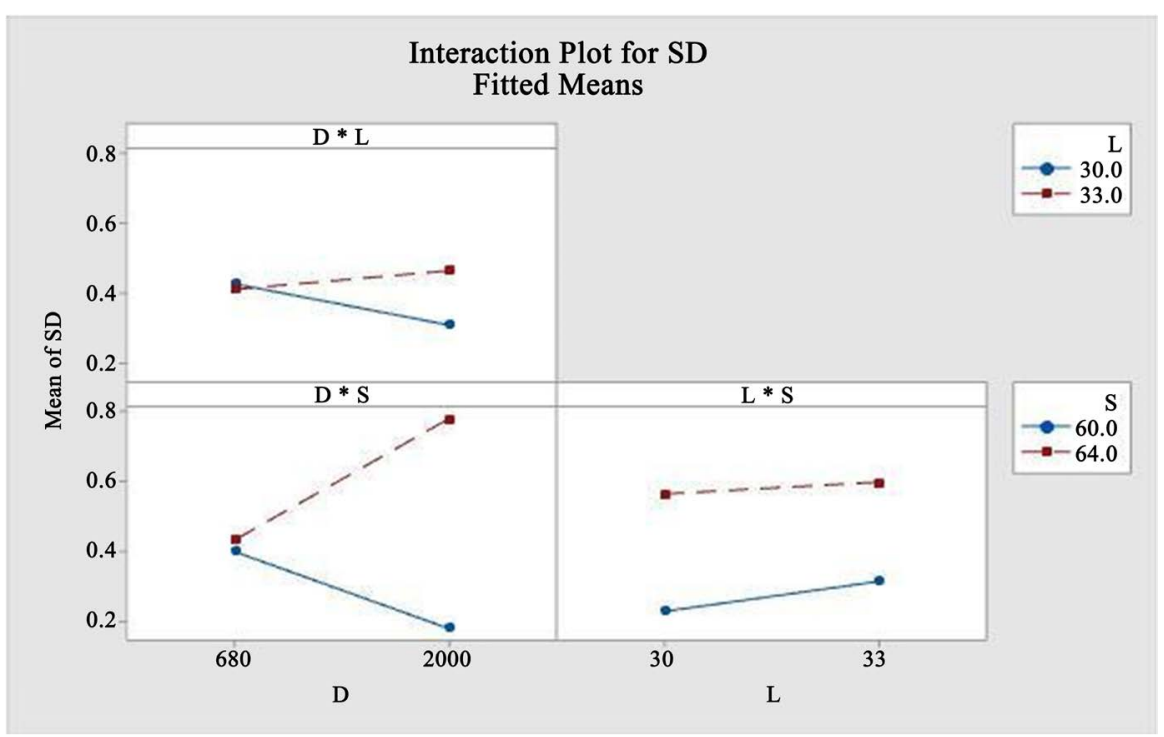

Figure 5. Interaction plot for standard deviation.

for the workstation can be determined. It is observed that variability is lowest when both material density and the length of the table are at a low level. So, the optimized design parameters for the workstation are:

$$
\begin{aligned}
& \text { Material Density (D): Low Level }\left(2000 \mathrm{~kg} / \mathrm{m}^{3}\right) \\
& \text { Length of the Table (L): Low Level }(30 \mathrm{~cm}) \\
& \text { Length of the Stand (S): Low Level }(60 \mathrm{~cm})
\end{aligned}
$$

The above design parameter will allow "maximum foldability" which in turn means "minimum folding time" will be achieved by using this combination of design parameters in the product design and development phase.

\section{Conclusion}

In this research article, a portable workstation is considered whose foldability 
process is subjected to improvement using DoE method. The main goal of this research was to determine the optimal time needed to fold the workstation. This process depends on three factors which significantly affect folding time. These factors are varied into two levels-high level and low level to observe the impact on the folding time. The interactions of the factors are also evaluated because, quality characteristics should preferably be additive (i.e. no interaction exists among the quality characteristics) and monotonic (i.e. the effect of each factor on robustness should be in a consistent direction, even when the settings of factors are changed), but it is often seen in practical situation that even though the main factors have no or little impact on the variability of a response, the interaction between those factors has a significant impact on that [11]. Therefore, this research article considers the interactions between the factors in order to detect any impact on the variability of the folding time of the workstation. Main and interaction plots in terms of standard deviation are also determined. After analyzing the variability and mean folding time using full factorial design of experiment, the optimal design parameters are determined. However, as an early stage design, only two-level factorial design has conducted here. In future as a further work, 3 or 4 level factorial design can be evaluated to determine more efficient parameters and increase the competence level of the design.

\section{Conflicts of Interest}

The authors declare no conflicts of interest regarding the publication of this paper.

\section{References}

[1] Wang, F.K., Yeh, C.T. and Chu, T.P. (2016) Using the Design for Six Sigma Approach with TRIZ for New Product Development. Computers \& Industrial Engineering, 98, 522-530. https://doi.org/10.1016/j.cie.2016.06.014

[2] Schuh, G., Prote, J.P., Dany, S., Molitor, M. and Pagano, L. (2018) Adaptation of a Product Maturity Model to Highly Iterative Product Development. Proceedings of the 2017 IEEE International Conference on Industrial Engineering and Engineering Management, Singapore, 10-13 December 2017, 485-489. https://doi.org/10.1109/IEEM.2017.8289938

[3] Singh, B., Kumar, R. and Ahuja, N. (2005) Optimizing Drug Delivery Systems Using Systematic "Design of Experiments". Part I: Fundamental Aspects. Critical Reviews in Therapeutic Drug Carrier Systems, 22, 27-105. https://doi.org/10.1615/CritRevTherDrugCarrierSyst.v22.i1.20

[4] Verma, S., Lan, Y., Gokhale, R. and Burgess, D.J. (2009) Quality by Design Approach to Understand the Process of Nanosuspension Preparation. International Journal of Pharmaceutics, 377, 185-198. https://doi.org/10.1016/j.ijpharm.2009.05.006

[5] Kosierb, A., Merkwirth, C., Pedrys, R. and Psonka-Antonczyk, K. (2019) Optimization of Parameters of the Linear TOF-SIMS Spectrometer by DOE Method. Vacuum, 83, 137-139. https://doi.org/10.1016/j.vacuum.2009.01.046

[6] Das, A.K. and Dewanjee, S. (2018) Chapter 3: Optimization of Extraction Using Mathematical Models and Computation. Computational Phytochemistry, 75-106. 
https://doi.org/10.1016/B978-0-12-812364-5.00003-1

[7] Kulkarni, S. (2016) Process Development Part 2: Exploring the Dimensional Process via the DOE. Robust Process Development and Scientific Molding, 225-267. https://doi.org/10.3139/9781569905876.009

[8] Antony, J. (2007) Full Factorial Designs. Design of Experiments for Engineers and Scientists.

[9] Antony, J. (2003) A Systematic Methodology for Design of Experiments. Design of Experiments for Engineers and Scientists. https://doi.org/10.1016/B978-075064709-0/50005-3

[10] Kleijnen, J.P.C. (2008) Screening Designs. International Series in Operations Research and Management Science, 111. https://doi.org/10.1007/978-0-387-71813-2_6

[11] Antony, J. (2002) Some Key Things Industrial Engineers Should Know about Experimental Design. Logistics Information Management, 11, 386-392.

https://doi.org/10.1108/09576059810242606 